\title{
ОПРЕДЕЛЕНИЕ НИТРИТ-ИОНОВ В КОЛБАСНЫХ ИЗДЕЛИЯХ И ПОКАЗАТЕЛЕЙ КАЧЕСТВА МОЛОКА
}

\author{
Л.С. Егорова, Е.А. Лейтес, К.В. Греку, Е.Ю. Евдокимова
}

\begin{abstract}
В работе представлен тест-метод определения нитрит-ионов, в основе которого лежит реакция Грисса - диазотирования и азосочетания с образованием азокрасителя, адаптированный для анализа пищевых продуктов, в частности колбасных изделий, путем замены носителя. Выбор методики обусловлен следующими причинами: доступность используемых реактивов, отсутствие сложной, дорогостоящей аппаратуры, простота выполнения, экспрессность. Учтены требования к аналитическим реагентам: контрастность иветовой шкалы, высокая скорость взаимодействия с определяемым компонентом. Изготовлены индикаторные трубки и создана стандартная цветовая шкала для быстрого определения содержания нитрит-ионов. Тест-метод апробирован на содержание нитрит-ионов в колбасных изделиях. Диапазон определяемых содержаний нитрит-ионов составляют 0,05-0,28 мка/мл, время определения 15-20 минут.
\end{abstract}

Для определения показателей качества молока использованы химические и фризикохимические методы анализа. Определены титруемая кислотность, буфрерная ёмкость, массовая доля лактозы и кальция - титриметрическими методам анализа. Гравиметрическим методом установлено содержание сухих веществ и воды. Активная кислотность (pH) определена потенциометрическим методом, плотность - при помощи ареометра. Практически все образцы молока имеют показатели, соответствующие ГОСТу. Наибольшие отклонения в показателях качеств, а молока выявлены в образце «Биоснежка» ООО «Биоснежка» 2. Барнаул.

Ключевые слова: нитрит-ионы, диазотирование, 1-нафтиламин, 1-(4-аминонафтилазо)бензол-4-сульфоновая кислота, показатели качества молока, массовая доля лактозы, массовая доля кальция.

\section{ВВЕДЕНИЕ}

Полноценное и безопасное питание населения является одним из важных фракторов сохранения здоровья. Самыми полноценными считаются продукты животного происхождения, мясные и молочные. В целях охраны здоровья на предприятиях, где существуют вредные условия труда, работники получают молоко. Благодаря содержанию в нем кальция, фосфора, витаминов предотвращается развитие авитаминозов. Молоко является качественным продуктом питания и сырьем для молочной промышленности только в том случае, если в нем содержится нормальное количество питательных веществ, а органолептические и санитарно-гигиенические показатели соответствует требованиям стандартов. В последние годы получаемая основная масса товарного молока производится в частном секторе агропромышленного комплекса, поэтому очень важно изучить качественные показатели данной продукции. Безопасность мясных изделий, в частности колбас, зависит от количества нитритов, добавляемых в качестве кон- серванта и для придания розового цвета (пищевая добавка E 250). Превышение содержания нитритов приводит к кислородному голоданию организма и имеет канцерогенный эффект. Они могут выступать в качестве агентов, обладающих противовоспалительными и антимикробными свойствами, проявлять антидепрессантную и противосудорожную активность. Цель данной работы - определение нитрит-ионов в колбасных изделиях и показателей качества молока.

\section{ЭКСПЕРИМЕНТАЛЬНАЯ ЧАСТЬ}

В качестве объектов исследования выбрано молоко разных производителей, приобретенное в торговых точках г. Барнаула, по итогам проведенного социологического опроса: «Алтайская буренка» ООО «Алтайская буренка» г. Барнаул; «Молочная сказка» ЗАО «Барнаульский молочный комбинат» г. Барнаул; «Простоквашино» ОАО «Кемеровский молочный комбинат» г. Кемерово; «Коровкино» ЗАО «Барнаульский молочный комбинат» г. Барнаул; «Домик в деревне» ОАО «Вимм- 


\section{ОПРЕДЕЛЕНИЕ НИТРИТ-ИОНОВ В КОЛБАСНЫХ ИЗДЕЛИЯХ И ПОКАЗАТЕЛЕЙ КАЧЕСТВА МОЛОКА}

Билль-Данн» г. Москва; «Биоснежка» ООО «Биоснежка» г. Барнаул. Колбасные изделия ООО«Барнаульский пищевик»: колбаса молочная, вареная категории Б ГОСТ Р 521962011 ; колбаса чайная, вареная категории Б ГОСТ Р 52196-2011; колбаса русская, вареная ГОСТ Р 52196-2011.

Для определения показателей качества молока использованы химические и физикохимические методы анализа. Определены титруемая кислотность, буферная ёмкость, массовая доля лактозы и кальция - титриметрическими методам анализа. Гравиметрическим методом установлено содержание сухих веществ и воды. Активная кислотность $(\mathrm{pH})$ определена потенциометрическим методом, плотность - при помощи ареометра [1-6].

\section{РЕЗУЛЬТАТЫ И ИХ ОБСУЖДЕНИЕ}

Сравнения показателей по сезонам осень - весна выявило, что осенние показа- тели менее отклонялись от норм, что связано с лучшим питанием и содержанием коров в данный период. Весенние показатели качества значительно хуже, на что повлияли малопитательные корма, а так же период восстановления после родов и лактации коров.

По показателям содержания кальция и pH все образцы соответствуют ГОСТу (таблицы 1, 2), по показателям буферной емкости (по щелочи) и титруемой кислотности отклонения наблюдаются в образце под названием «Алтайская буренка» ООО «Алтайская буренка» г. Барнаул. Показатели буферной емкости (по кислоте) незначительно ниже в образцах: «Биоснежка» ООО «Биоснежка» г. Барнаул и «Коровкино» ЗАО «Барнаульский молочный комбинат» г. Барнаул; содержание лактозы снижено в образце «Биоснежка» ООО «Биоснежка» г. Барнаул; содержание воды превышено на 5-8 \%, согласно нормативному документу (ГОСТ 3626-73) в образце «Биоснежка» ООО «Биоснежка» г. Барнаул.

Таблица 1 - Показатели качества молока $(\mathrm{n}=3, \mathrm{P}=0,95)$

\begin{tabular}{|c|c|c|c|c|}
\hline № образца & $\begin{array}{c}\text { Сухой молочный } \\
\text { остаток, \% }\end{array}$ & $\begin{array}{c}\text { Массовая } \\
\text { доля воды, \% }\end{array}$ & $\begin{array}{c}\text { Буферная } \\
\text { емкость } \\
\text { по кислоте }\end{array}$ & $\begin{array}{c}\text { Буферная } \\
\text { емкость } \\
\text { по щелочи }\end{array}$ \\
\hline Алтайская буренка & $11,69 \pm 0,02$ & $88,31 \pm 0,02$ & $1,60 \pm 0,01$ & $0,88 \pm 0,02$ \\
\hline Молочная сказка & $13,74 \pm 0,02$ & $86,26 \pm 0,02$ & $1,63 \pm 0,01$ & $0,99 \pm 0,01$ \\
\hline Домик в деревне & $12,21 \pm 0,02$ & $87,79 \pm 0,02$ & $1,74 \pm 0,01$ & $1,18 \pm 0,01$ \\
\hline Коровкино & $19,01 \pm 0,02$ & $80,99 \pm 0,02$ & $1,52 \pm 0,01$ & $1,01 \pm 0,01$ \\
\hline Простоквашино & $17,37 \pm 0,01$ & $82,53 \pm 0,02$ & $1,57 \pm 0,01$ & $1,09 \pm 0,01$ \\
\hline Биоснежка & $5,94 \pm 0,01$ & $94,06 \pm 0,02$ & $1,54 \pm 0,01$ & $1,03 \pm 0,01$ \\
\hline $\begin{array}{c}\text { Соответствие } \\
\text { показателей по ГОСТу }\end{array}$ & $11.00-13.00$ & $87.00-89.00$ & $1,60-2,50$ & $1,00-1,40$ \\
\hline
\end{tabular}

Таблица 2 - Показатели качества молока $(\mathrm{n}=3, \mathrm{P}=0,95)$

\begin{tabular}{|c|c|c|c|c|}
\hline № образца & $\mathrm{pH}$ & $\begin{array}{c}\text { Титруемая } \\
\text { кислотность, } \text { от }\end{array}$ & $\begin{array}{c}\text { Массовая доля } \\
\text { лактозы, \% }\end{array}$ & $\begin{array}{c}\text { Массовая доля } \\
\text { кальция, мг\% }\end{array}$ \\
\hline Алтайская буренка & $6,58 \pm 0,02$ & $14,33 \pm 0,01$ & $4,67 \pm 0,02$ & $109,24 \pm 0,02$ \\
\hline Молочная сказка & $6,66 \pm 0,01$ & $15,33 \pm 0,01$ & $5,03 \pm 0,01$ & $105,78 \pm 0,05$ \\
\hline Домик в деревне & $6,65 \pm 0,01$ & $18,33 \pm 0,02$ & $5,03 \pm 0,01$ & $113,12 \pm 0,02$ \\
\hline Коровкино & $6,68 \pm 0,01$ & $15,33 \pm 0,02$ & $5,03 \pm 0,01$ & $102,46 \pm 0,01$ \\
\hline Простоквашино & $6,55 \pm 0,01$ & $18,00 \pm 0,02$ & $4,67 \pm 0,01$ & $116,10 \pm 0,02$ \\
\hline Биоснежка & $6,65 \pm 0,01$ & $16,00 \pm 0,02$ & $4,38 \pm 0,01$ & $102,71 \pm 0,02$ \\
\hline $\begin{array}{c}\text { Соответствие } \\
\text { показателей по ГОСТу }\end{array}$ & $6,47-6,67$ & $16.00-18.00$ & $4.50-5.00$ & $100-140$ \\
\hline
\end{tabular}

Определение нитрит-ионов проводилось тест-методом по методике для анализа сточных вод и почв [7, 8], модифицированной тем, что бумага-основа марки $\mathrm{F}$ с фильтровальной способностью 40 мм/мин заменена на индикаторные трубки. В основе применяемого ме- 
тода лежит реакция Грисса - реакция диазотирования и азосочетания с образованием азокрасителя при $\mathrm{pH}=2-4$ (см. схему реакции) [9, 10].

В случае появления при смешивании растворов розовой окраски добавляли цинковую пыль. При действии цинка в присутствии уксусной кислоты нитрат-ионы восстанавливаются до нитрит-ионов:

$$
\begin{aligned}
& \mathrm{NO}_{3}^{-}+\downarrow \mathrm{Zn}+2 \mathrm{CH}_{3} \mathrm{COOH} \rightarrow \\
& \rightarrow \mathrm{NO}_{2}^{-}+\mathrm{Zn}^{2+}+2 \mathrm{CH}_{3} \mathrm{COO}^{-}+\mathrm{H}_{2} \mathrm{O}
\end{aligned}
$$

Индикаторные трубки готовили путем запаивания одного конца. Затем помещали 0,50 мл заранее приготовленного реактива Грисса и заклеивали сверху лейкопластырем медицинским.

Для создания стандартной цветовой шкалы использовали ГСО 7479-98 $\left(\mathrm{C}\left(\mathrm{NO}_{2}^{-}\right)=\right.$ 1,00 мг/мл). При внесении в индикаторные трубки 0,50 мл рабочих растворов наблюда- лось появление розовой окраски и ее изменение в зависимости от концентрации определяемого компонента. Пробоподготовку проводили методом квартования, затем пробу дважды измельчали в блендере. 12,50 г пробы, подготовленной к анализу, помещали в мерную колбу вместимостью 250 мл, доводили дистиллированной водой до метки и перемешивали. Колбу с содержимым нагревали на водяной бане, периодически встряхивая, до $(55 \pm 2){ }^{\circ} \mathrm{C}$ в течение 5 мин. Затем вытяжку фильтровали через бумажный фильтр «Красная лента», не перенося осадка на фрильтр. В мерную колбу вместимостью 100 мл вносили пипеткой 10 мл обезбелоченного фильтрата, доводили дистиллированной водой до метки и перемешивали. Интенсивность окраски реакционной зоны оценивали по стандартной цветовой шкале.
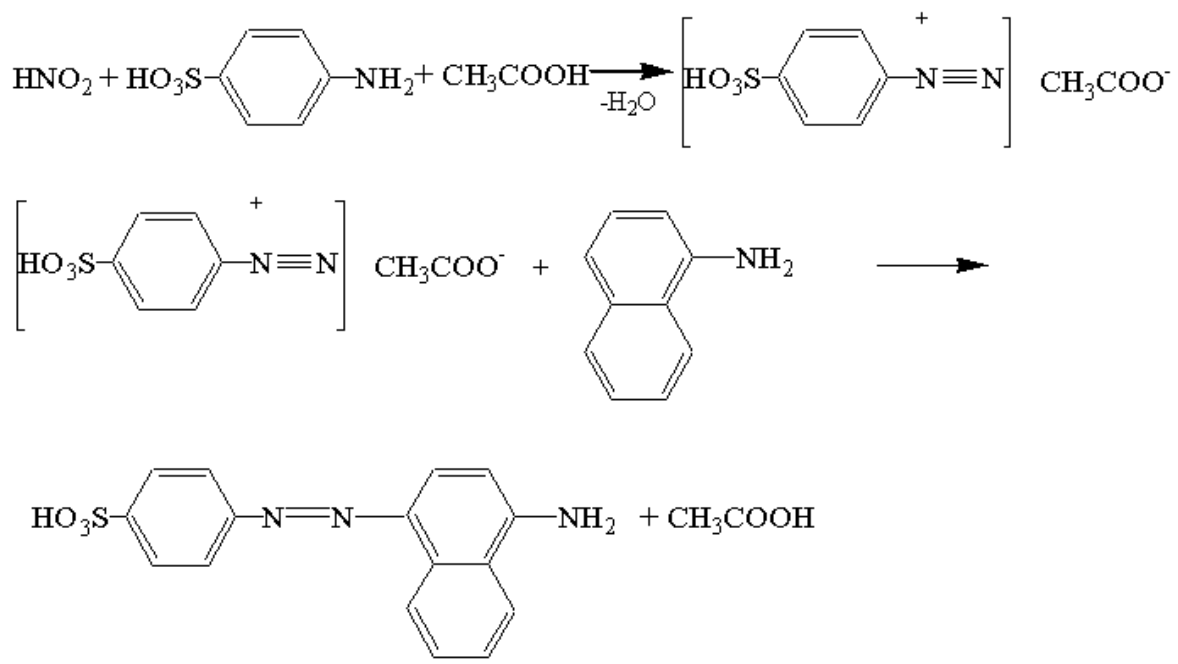

Рисунок 1 - Схема реакции

Массовую долю нитрит-ионов (X) в процентах вычисляли по формуле:

$$
\mathrm{X}=\frac{\mathrm{M} * 250 * 100 * 100}{\mathrm{~m} * \mathrm{v} * 10^{6}}
$$

где $\mathrm{M}$ - массовая концентрация нитрит-ионов, найденная по стандартной цветовой шкале; m - масса продукта, г; v - количество фильтрата, мл; $10^{6}$ - коэффицциент перевода в граммы.

Время анализа составляет 15-20 минут. Результаты анализа представлены в таблице 3. Правильность метода контролировали фотометрическим методом Грисса-Илосвая, в котором образование промежуточной соли диазония при взаимодействии нитрита с сульфаниловой кислотой происходит по ре- акции, в которой образуется 1-(4аминонафтилазо)-бензол-4-сульфоновая кислота - краситель красного цвета (см. рисунок 1). Условия проведения этих реакций уточнялись: диазотирование должно проводиться в сильнокислых растворах на холоду, сочетание должно быть проведено только после того, как полностью закончится диазотирование и при возможно более низкой кислотности. Это должно быть учтено при подготовке реактивов (сульфаниловой кислоты и 1нафтиламина). Для стабилизации $\mathrm{pH}$ в реакции сочетания использовали раствор ацетата натрия. Оптическую плотность образовавшегося красителя измеряют при 520 нм в кювете с толщиной слоя $1 \mathrm{~cm}$. 


\section{ОПРЕДЕЛЕНИЕ НИТРИТ-ИОНОВ В КОЛБАСНЫХ ИЗДЕЛИЯХ И ПОКАЗАТЕЛЕЙ КАЧЕСТВА МОЛОКА}

Таблица 3 - Результаты определения нитрит-ионов в мясных продуктах $(\mathrm{n}=3, \mathrm{P}=0,95)$

\begin{tabular}{|c|c|c|c|}
\hline Объект анализа & $\begin{array}{c}\text { Найдено } \\
\text { тест-методом, } \\
\%\left(10^{3}\right)\end{array}$ & $\begin{array}{c}\text { Найдено } \\
\text { фотометрическим } \\
\text { методом, \% }\left(10^{3}\right)\end{array}$ & $\begin{array}{c}\text { Срок реализации при температуре } \\
\text { хранения от 0 }{ }^{\circ} \mathrm{C} \text { до }+6^{\circ} \mathrm{C} \text { и } \\
\text { относительной влажности } 75 \pm 5, \%\end{array}$ \\
\hline Образец 1 & $2 \pm 1$ & $2,3 \pm 0,8$ & 30 суток \\
\hline Образец 2 & $3 \pm 1$ & $3,0 \pm 0,8$ & 60 суток \\
\hline Образец 3 & $3,2 \pm 0,7$ & $3,4 \pm 0,8$ & 30 суток \\
\hline
\end{tabular}

Примечание: Образец 1 - колбаса молочная, вареная категории Б ГОСТ Р 52196-2011; Образец 2 - колбаса чайная, вареная категории Б ГОСТ Р 52196-2011; Образец 3 - колбаса русская, вареная ГОСТ Р 52196-2011.

Для построения градуировочного графика (см. рисунок 2) использовали ГСО 7479-98 $\left(\mathrm{C}\left(\mathrm{NO}_{2}^{-}\right)=1,00 \mathrm{mг} / \mathrm{Mл}\right)$. Для этого в колбу на 100 мл добавляли 1,00 мл ГСО и доводили до метки дистиллированной водой $\left(\mathrm{C}\left(\mathrm{NO}_{2}^{-}\right)=\right.$ 10,00 мкг/мл). Рабочие растворы меньших концентраций 0,$05 ; 0,10 ; 0,15 ; 0,18 ; 0,20$; 0,25 мкг/мл готовили последовательным разбавлением исходного раствора дистиллированной водой. Стандартные растворы нитритиона не стойки, поэтому их готовят непосредственно перед построением градуировочного графрика.

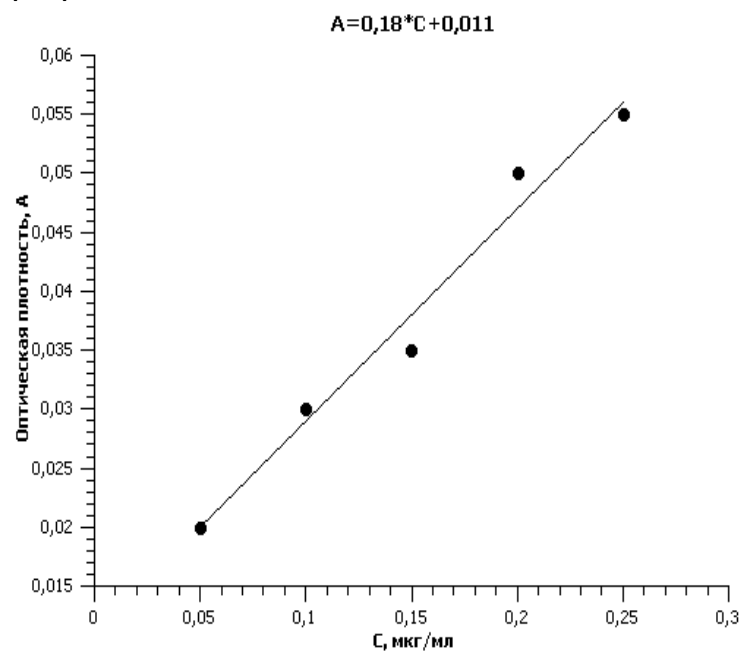

Рисунок 2 - Зависимость оптической плотности от концентрации нитрит-ионов

Массовая доля нитрит-ионов не должна превышать $0,005 \%$. Из результатов анализа можно сделать выводы, что образцы содержат нитрит-ионы не выше допустимого значения.

\section{ЗАКЛЮЧЕНИЕ}

Таким образом, тест-метод определения нитрит-ионов в сточных водах и почве адаптирован для анализа пищевых продуктов путем замены носителя. Выбор методики обусловлен следующими причинами: доступ- ность используемых реактивов, отсутствие сложной, дорогостоящей аппаратуры, простота выполнения, экспрессность. Учтены требования к аналитическим реагентам: контрастность цветовой шкалы, высокая скорость взаимодействия с определяемым компонентом. Изготовлены индикаторные трубки и создана стандартная цветовая шкала для быстрого определения содержания нитритионов. Тест-метод апробирован на содержание нитрит-ионов в колбасных изделиях. Диапазон определяемых содержаний нитритионов составляют 0,05-0,28 мкг/мл, время определения 15-20 минут.

Практически все образцы молока имеют показатели, соответствующие ГОСТу. Наибольшие отклонения в показателях качества молока выявлены в образце «Биоснежка» ООО «Биоснежка» г. Барнаул.

\section{СПИСОК ЛИТЕРАТУРЫ}

1. Фомина, О. Н. Молоко и молочные продукты / О. Н. Фомина. - М. «Протектор», 2011. - 880 с.

2. Барабанщиков, Н.В. Молочное дело / Н. В. Барабанщиков. - М. : Агропромиздатю, 1990. $-414 \mathrm{c}$.

3. ГОСТ 3624-92 Молоко и молочные продукты. Титриметрические методы определения кислотности. - М. : Стандартинформ, 2009. - 8 с.

4. ГОСТ 3626-73 Молоко и молочные продукты. Методы определения влаги и сухого вещества. - М. : Стандартинформ, 2009.. - 11с.

5. ГОСТ Р 55331-2012 Молоко и молочные продукты. Методы определения содержания кальция. - М. : Стандартинформ, 2013. - 8 с.

6. ГОСТ Р 51259-99. Молоко и молочные продукты. Методы определения лактозы и галактозы. - М. Госстандарт России, 2000. -6 с.

7. Островская В. М. Вода индикаторные системы / В. М. Островская. - М. Мир, 2002. - 265 с.

8. Медико-биологические требования и санитарные нормы качества продовольственного сырья и пищевых продуктов. - М. Изд-во стандартов, 1990. - 186 c.

9. Егорова, Л. С. Тест-определение нитритов в пищевых продуктах / Л. С. Егорова, А. М. Канда- 
урова // Известия Алтайского государственного университета. - 2011. - № 3-1. - С. 104-107.

10. ГОСТ 9792-73. Отбор и подготовка проб колбасных изделий. - М. Из-во стандартов, 1993. $6 \mathrm{c.}$

Егорова Людмила Сергеевна - к.х.н., доцент кафредры техносфрерной безопасности и аналитической химии АлтГУ, e-mail: egorova@chem.asu.ru.
Лейтес Елена Анатольевна - к.х.н., доцент кафредры техносфрерной безопасности и аналитической химии АлтГУ, e-mail: leites-elena@yandex.ru.

Греку Ксения Владимировна - студентка 601 гр химического фракультета АлтГУ, тел.: 8-913-219-48-58.

Евдокимова Елена Юрьевна - студентка 661М гр химического фракультета АлтГУ, тел.: 8-960-942-02-32. 